\title{
Role of Bone Morphogenic Protein 2 in Retinal Patterning and Retinotectal Projection
}

\author{
Hiraki Sakuta, Hiroo Takahashi, Takafumi Shintani, Kazuma Etani, Akihiro Aoshima, and Masaharu Noda \\ Division of Molecular Neurobiology, National Institute for Basic Biology and School of Life Science, The Graduate University for Advanced Studies, \\ Myodaiji-cho, Okazaki 444-8787, Japan
}

It has been long believed that the anteroposterior (A-P) and dorsoventral (D-V) axes in the developing retina are determined independently and also that the retinotectal projection along the two axes is controlled independently. However, we recently demonstrated that misexpression of Ventroptin, a bone morphogenic protein (BMP) antagonist, in the developing chick retina alters the retinotectal projection not only along the $\mathrm{D}-\mathrm{V}$ (or mediolateral) axis but also along the A-P axis. Moreover, the dorsal-high expression of BMP4 is relieved by the dorsotemporal-high expression of $B M P 2$ at embryonic day 5 (E5) in the retina, during which Ventroptin continuously counteracts the two BMPs keeping on the countergradient expression pattern, respectively. Here, we show that the topographic molecules so far reported to have a gradient only along the D-V axis and ephrin-A2 so far only along the A-P axis are both controlled by the BMP signal, and that they are expressed in a gradient manner along the tilted axis from E6 on in the developing chick retina: the expression patterns of these oblique-gradient molecules are all changed, when BMP2 expression is manipulated in the developing retina. Furthermore, in both BMP2 knockdown embryos and ephrin-A2-misexpressed embryos, the retinotectal projection is altered along the two orthogonal axes. The expressional switching from $B M P 4$ to $B M P 2$ thus appears to play a key role in the retinal patterning and topographic retinotectal projection by tilting the $\mathrm{D}-\mathrm{V}$ axis toward the posterior side during retinal development. Our results also indicate that $B M P 2$ expression is essential for the maintenance of regional specificity along the revised $\mathrm{D}-\mathrm{V}$ axis.

Key words: retina; retinotectal projection; BMP2; Ventroptin; ephrin-A2; chick

\section{Introduction}

Topographic maps are formed in various regions of the brain, and the projection from the retina to the tectum has been a good model system with which to understand the development of topographic maps. During development, retinal ganglion cell axons grow from the eye to the optic tectum [the primary visual center in lower vertebrates or the superior colliculus (SC) in mammals] and form a topographic map of visual space. Since Sperry (1963) proposed his chemoaffinity hypothesis, many topographic molecules have been identified. In particular, Eph family of receptor tyrosine kinases and their ligands, the ephrins, have been shown to be involved in sculpturing the topographic connection. EphA receptors and their glycosylphosphatidylinositolanchored ephrin-A ligands are expressed in complementary gradients in both the retina and the tectum along the anteroposterior (A-P) axis and mediate axonal navigation by differential repulsion and branching of the nasal $(\mathrm{N})$ and the temporal $(\mathrm{T})$ axons along the A-P axis (Nakamoto et al., 1996; Monschau et al., 1997; Brown et al., 2000; Feldheim et al., 2000, 2004; Yates et al., 2001).

Received March 16, 2006; revised Sept. 3, 2006; accepted Sept. 6, 2006.

This work was supported by grants from the Ministry of Education, Culture, Sports, Science, and Technology of Japan and from the Core Research for Evolutional Science and Technology program of the Japan Science and Technology Agency. We thank H. Tanaka for the monoclonal antibody against ephrin-A2; Y. Ayabe, M. Gotoh, and M. Mizoguchi for technical assistance; and A. Kodama for secretarial assistance.

Correspondence should be addressed to Dr. Masaharu Noda, Division of Molecular Neurobiology, National Institute for Basic Biology, 5-1 Higashiyama, Myodaiji-cho, 0kazaki 444-8787, Japan. E-mail: madon@nibb.ac.jp. DOI:10.1523/JNEUROSCI.3027-06.2006

Copyright $\odot 2006$ Society for Neuroscience $\quad$ 0270-6474/06/2610868-11\$15.00/0
In addition, the $\mathrm{EphB}$ receptors and their transmembrane ephrin-B ligands have been shown to be important for the mapping of retinal axons along the mediolateral (M-L) axis (Hindges et al., 2002; Mann et al., 2002; McLaughlin et al., 2003b).

The graded distributions of these cell surface molecules are achieved by topographically expressed morphogens and transcription factors in the retina early on in development. Along the A-P axis, two winged-helix transcription factors Fox G1 (forkhead box G1) [CBF1 (chick brain factor 1)] and FoxD1 (CBF2) are expressed in the nasal and temporal regions of the developing chick retina at an early stage [peaking at embryonic day 3 (E3)], respectively, and determine the regional specificity in the retina by their counteraction (Yuasa et al., 1996; Takahashi et al., 2003). On the other hand, along the dorsoventral (D-V) axis, the counteraction between bone morphogenic protein 4 (BMP4) in the dorsal side and Ventroptin in the ventral side governs the regional specification in the retina at the early developmental stages (stage 11 to E5) (Sakuta et al., 2001). Subsequently, transcription factors Tbx5 (T-box 5) in the dorsal retina and $c \operatorname{Vax}$ (chick ventral anterior homeobox) in the ventral retina begin to be expressed under the control of the BMP4 signal (Koshiba-Takeuchi et al., 2000). At later stages (from E5 onward), in proportion to the disappearance of BMP4 expression from the dorsal retina, Ventroptin begins to be expressed in both a nasal high-temporal low and a ventral high-dorsal low gradient (oblique gradient) in the retina (V/N-high pattern). At the same time, BMP2 begins to be expressed in a oblique-gradient pattern complementary to that of Ventroptin along the two axes (D/T-high pattern). Thus, 


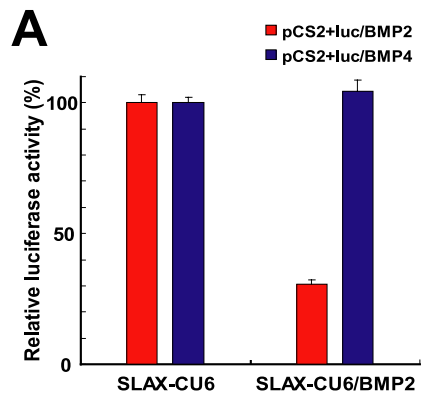

C

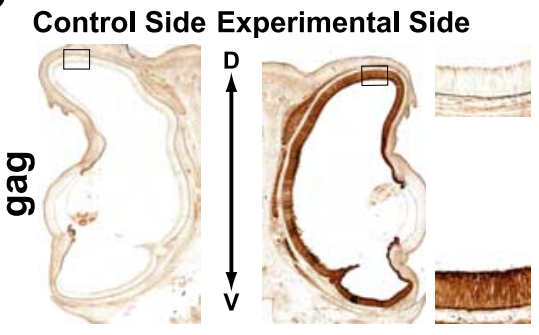

D

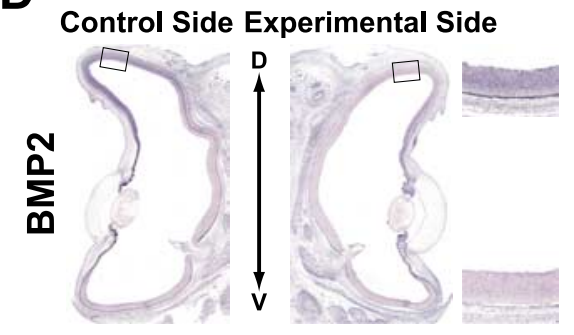

E

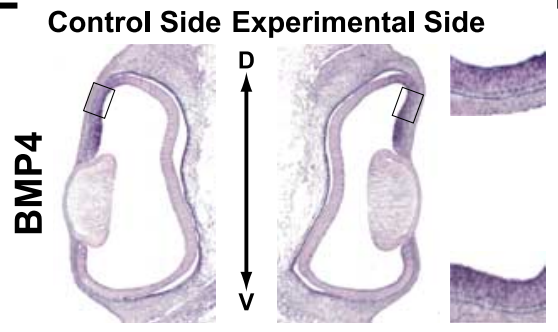

$\mathbf{F}$

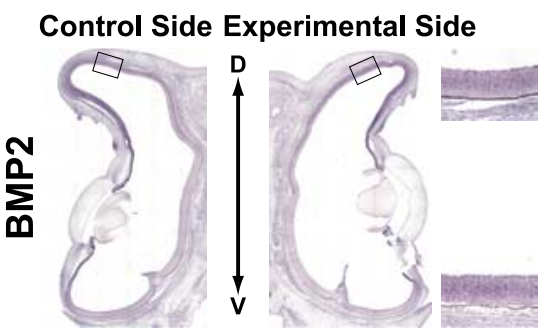

Figure 1. The gene-specific knockdown system for the chick. $A$, Functional analysis of the vector-based shRNA in CEF cells. CEFs were transfected with a reporter plasmid (pCS2 + luc/BMP2 or pCS2 + luc/BMP4) and an shRNA expression plasmid (SLAX-CU6 or SLAX-CU6/BMP2). Luciferase activity was measured $48 \mathrm{~h}$ after transfection. SLAX-CU6/BMP2 selectively knocked down the luciferase expression from the reporter plasmid containing the BMP2 sequence. Luciferase activity in the cells transfected with an empty vector SLAX-CU6 was set to $100 \%$. Error bars indicate SD. B, Schematic representation of the RCASDC retroviral vector. The shRNA-expressing cassette was inserted into the U3 region of the $3^{\prime}$ LTR of the RCASDC. The resultant provirus acquires the shRNA-expressing cassette sequences at both ends by duplication of the LTR during the reverse transcription and integrates them into the genome of transfected cells. C, Expression of viral gag protein in the right eye transfected. RCASDC-CU6/BMP2 was introduced to the embryo at E1.5 by electroporation. Viral gag protein was visualized at E8 by immunostaining with monoclonal antibody 3C2. D, E, Coronal section in situ hybridization of control retinas (left) and RCASDC-CU6/BMP2-electroporated retinas (right). Expression of BMP2 at E8 was markedly reduced in the retina by electroporation of RCASDC-CU6/BMP2 (D). Expression of BMP4 at E4 was not altered by electroporation of RCASDC-CU6/BMP2 (E). $\boldsymbol{F}$, Coronal section in situ hybridization of the retinas at E8 electroporated with RCASDC-CU6/EGFP (right) at E1.5. Expression of BMP2 was not changed by the expression of shRNA for EGFP. The boxed regions in the control retina (left) and manipulated retina (right) are enlarged on the top right and bottom right sides, respectively $(\boldsymbol{C}-\boldsymbol{F})$.

the counteraction between BMP4 and Ventroptin is relieved by that between BMP2 and Ventroptin. Recently, we revealed that Fox $G 1$ expression in the nasal retina represses BMP2 expression through inhibition of the BMP signal, and thereby the obliquegradient expression patterns of BMP2 and Ventroptin are induced (Takahashi et al., 2003). Furthermore, when Ventroptin was misexpressed in the developing retina, temporal axons extended to the posterior end of the tectum as a result of the induction of ephrin-A2 expression in the temporal retina (Sakuta et al., 2001). These findings are the first demonstration of functional interactions between the regulatory molecules along the two axes.

In the present study, to gain insight into the details of the interaction between the two axes underlying control mechanisms of the retinotectal projection, we investigated the role of BMP2, which begins to be expressed in a oblique gradient in the retina from E6 on when the projection indeed occurs. To achieve this aim, we developed gene-specific knockdown and reagent- inducible gene expression systems for the chick. Here, we show that BMP2 controls the expression of the topographic molecules along the D-V axis and ephrin- $A 2$ in the developing chick retina and thereby plays a key role in the topographic retinotectal projection along both the A-P and the M-L axes.

\section{Materials and Methods}

Plasmid construction. The chick U6 promoter (CU6) region was PCR amplified from chick genomic DNA using as primers $5^{\prime}$-GCTCTAGACCTTAAAGTCCCACCAAAAC- ${ }^{\prime}$ ' and CGGATCCCGTCTCCGAATATCTTGACCTCCTAG. The PCR product was digested with $\mathrm{Xba \textrm {I }}$ and $\mathrm{BamHI}$ and inserted into the $\mathrm{Xba \textrm {I }} /$ $B a m H I$ sites of the vector SLAX-NS (Suzuki et al., 2000) to yield SLAX-CU6. The oligonucleotides sequences used for the construction of $B M P 2$ and enhanced green fluorescent protein (EGFP) short-hairpin RNA (shRNA) were as follows: BMP2 forward, ATTCGGTCGTACTTAAGAACTATTTCAAGAGAATAGTTCTTTAGTACGACCTTTTTGGAAA; BMP2 reverse, CTAGTTTCCAAAAAGGTCGTACTAAAGAACTATTCTCTTGAAATAGTTCTTAAGTAC-GACC; EGFP forward, ATTCGGAGTTGTCGCAATTCTTGTTCAA-GAGACAAGAATTGGGACAACTCCTTTTTGGAAA and EGFP reverse, CTAGTTTCCAAAAAGGAGTTGTCCCAATTCTTGTCTCTTGAACAAGAATTGCGACAACTCC. To prevent selftargeting of the shRNA to the viral genomic RNA, a single mutation (underlined characters) was introduced in the sense strand of the shRNA sequence (Yu et al., 2002). The oligonucleotides were annealed and cloned into the BsmBI/SpeI sites of SLAX-CU6 to yield SLAX-CU6/BMP2 and SLAX-CU6/EGFP, respectively.

To generate the RCASDC vector, we inserted a polylinker sequence, AATGTAGTCTTATGCGGCCGCGGCGCGCCACTAGT, into the $5^{\prime}$ end of the $3^{\prime}$ long terminal repeat (LTR) of the RCASBP(B) vector (Hughes et al., 1987) according to a strategy described previously (Hantzopoulos et al., 1989). The polylinker contains a $15 \mathrm{bp}$ sequence of the $5^{\prime}$ region of the $\mathrm{U} 3$ region in LTR, which allows the foreign sequence to integrate into the host genome (Aiyar et al., 1996), together with three restriction sites [NotI, AscI, and SpeI, all unique to the RCASBP(B) vector]. The NotI/SpeI fragments of SLAX-CU6/BMP2 and SLAX-CU6/EGFP were inserted into the NotI/ SpeI sites of RCASDC to yield RCASDC-CU6/BMP2 and RCASDCCU6/EGFP, respectively.

pCS2 + (Turner and Weintraub, 1994) was digested with NotI and Bsp120I, and self-ligated to generate pCS2 $+\operatorname{NotI}(-)$. Oligonucleotides, CTAGGCGGCCGCATCGATACTAGTTCTAGAG (sense), and GATCCTCTAGAACTAGTATCGATGCGGCCGC (antisense) were annealed and inserted into the XbaI/BamHI sites of pGL3-Enhancer (Promega, Madison, WI) to make NotI, ClaI, and SpeI sites between. The coding region of firefly (Photinus pyralis) luciferase was isolated from this plasmid with $B g l \mathrm{II} / \mathrm{XbaI}$ digestion and inserted into the $\mathrm{BamHI} / \mathrm{XbaI}$ sites of pCS2 $+\operatorname{NotI}(-)$ to obtain pCS2 +luc. The coding region of chick BMP2 was cloned into the NotI/SpeI sites of pCS2+luc via the SLAX-NS vector to yield pCS2+luc/BMP2. The coding region of chick BMP4 was isolated from SLAX-NS/BMP4 (Sakuta et al., 2001) by NotI/SpeI digestion and cloned into the NotI/SpeI sites of pCS2+luc to yield pCS2+luc/BMP4. 
The tetracycline-responsive element (TRE) linked to the minimal cytomegalovirus promoter was isolated from pTRE2 (Clontech, Palo Alto, CA) and inserted into the RCAN$\mathrm{BP}(\mathrm{B})$ vector (Hughes et al., 1987) as an internal regulatory element to prepare RCAN-TRE. The ClaI fragment of SLAX-NS/BMP2 (Takahashi et al., 2003) was inserted into the ClaI site of the RCAN-TRE vector to yield RCAN-TRE/ BMP2. The protein-coding fragment of pEGFP-N1 (Clontech) was cloned into ClaI site of the RCAN-TRE vector via the SLAX-NS vector to yield RCAN-TRE/EGFP. The proteincoding fragment of reverse tetracyclinecontrolled transactivator (rtTA) of pTet-on (Clontech) was cloned into the ClaI site of the RCASDC vector via the SLAX-NS vector to generate RCASDC/rtTA.

The protein-coding fragment of chick ephrin-A2 was cloned into NotI/SpeI sites of the RCAS-NS (Suzuki et al., 2000) vector via the SLAX-NS vector to yield RCAS/ephrin-A2.

Luciferase assay. Chick embryonic fibroblasts (CEFs) were grown to $60 \%$ confluence in 96-well microplates. Cells were transfected with a combination of expression plasmids, pCS2+luc/BMP2 or pCS2+luc/BMP4 (10 ng), and SLAX-CU6 or SLAX-CU6/BMP2 (10 ng), together with phRL-TK (100 ng; Promega), using LipofectAmine Plus (Invitrogen, Carlsbad, CA). Luciferase activity was measured with a Dual-Glo Luciferase Assay System (Promega) using Fluoroskan Ascent FL (Labsystems, Helsinki, Finland) $48 \mathrm{~h}$ after transfection. Firefly luciferase activity was normalized using the sea pansy (Renilla) luciferase activity.

In ovo electroporation and doxycycline treatment. In ovo electroporation was performed as described previously (Sakuta et al., 2001). Retroviral constructs for the electroporation were suspended at a concentration of $0.25-1.0 \mu \mathrm{g} / \mu \mathrm{l}$ in PBS containing $0.05 \%$ fast green (Sigma, St. Louis, MO). Embryos were electroporated at Hamburger-Hamilton $(\mathrm{HH})$ stage $8-10$ and incubated in a humidified incubator. For doxycycline (DOX) treatment, DOX (100 $\mu$ l of 1 $\mathrm{mg} / \mathrm{ml}$ in PBS) or PBS $(100 \mu \mathrm{l})$ was administered to the embryos twice at E5 and E6.5 after electroporation. Embryos of normal size and morphology were used for assays.

In situ hybridization and riboprobes. Section and whole-mount in situ hybridization was performed according to protocols published previously (Suzuki et al., 2000). At least six sections from an embryo were analyzed to confirm that all sections have similar signal patterns for a topographic molecule. We analyzed the expression of topographic molecules by comparing the signals of the left (control side) and right (experimental side) eyes in the same section from several embryos $(n=3-9)$ for quantification analyses of a molecule. The templates used for digoxigenin-labeled RNA probes were as follows: the $557 \mathrm{bp}$ fragment of chick $T b \times 2$ (nucleotide residues 671-1227; GenBank accession number AF033668), the 512 bp fragment of chick Tbx3 (nucleotide residues 548-1059; GenBank accession number AF033669), the $501 \mathrm{bp}$ fragment of chick EphB2 (nucleotide residues 1532-2032; GenBank accession number NM_206951), the 470 bp fragment of chick EphB3 (nucleotide residues 2511-2980; GenBank accession number Z19061), the 500 bp fragment of chick ephrin-B1 (nucleotide residues 345-844; GenBank accession number NM_205035), the 567 bp fragment of chick ephrin-B2 (nucleotide residues 4-570; Gen-
Control Side Experimental Side
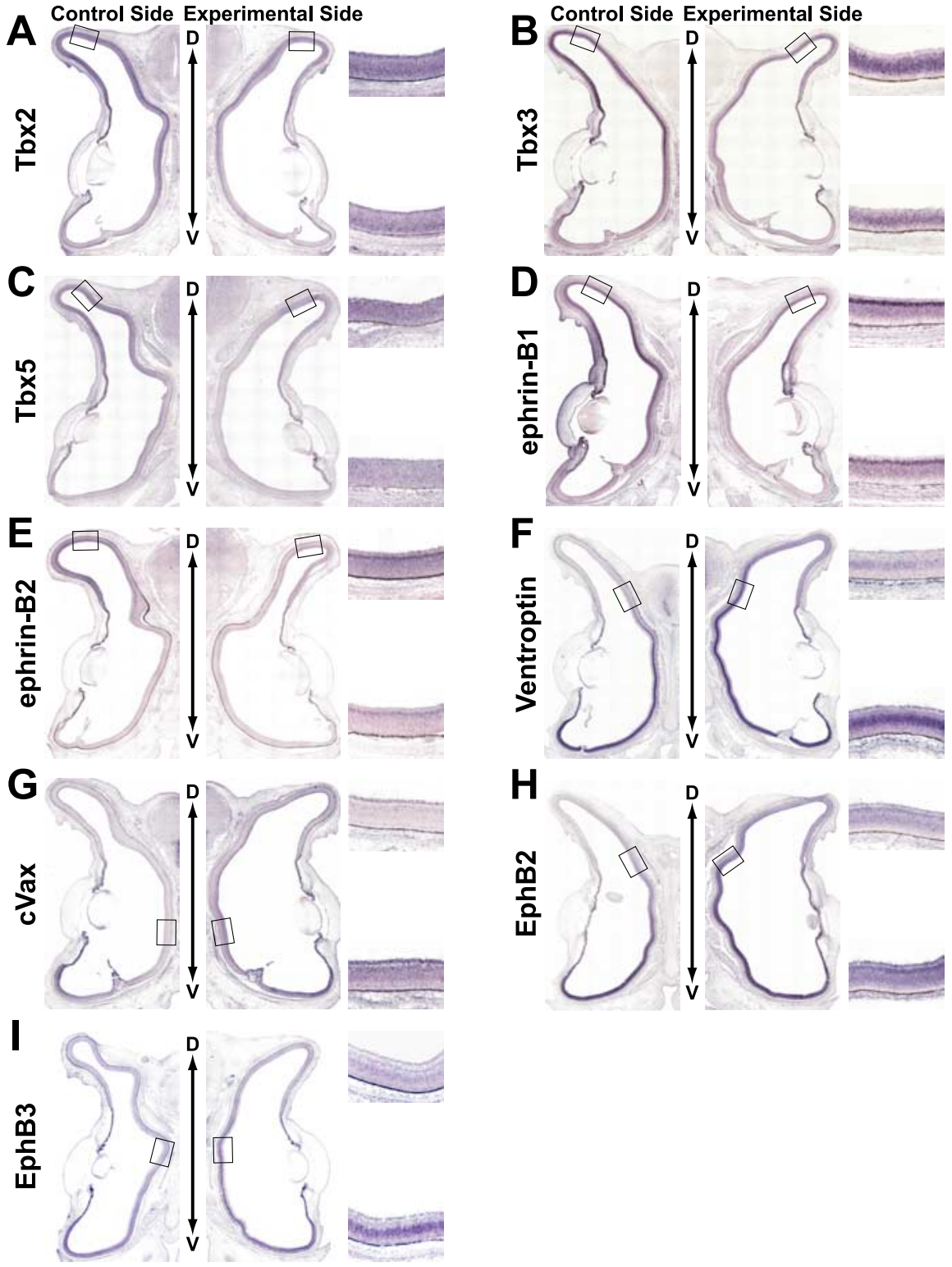

Figure 2. The effect of BMP2 knockdown on the expression of topographic molecules along the D-V axis. Coronal section in situ hybridization of control retinas (left) and electroporated retinas with RCASDC-CU6/BMP2 (right) of E8 embryos. Boxed regions were selected at the dorsal retina $(\boldsymbol{A}-\boldsymbol{E})$ and the dorsal-limit regions with the expression of the topographic molecules in the control retina $(\boldsymbol{F}-\boldsymbol{I})$ to clearly show the alteration in the expression by the manipulation. As for the analyses of the overall expression, see supplemental Figure 1 (available at www.jneurosci.org as supplemental material). The boxed regions in the sion of $\operatorname{Tbx2}(\boldsymbol{A}), \operatorname{Tbx} 3(\boldsymbol{B}), \operatorname{Tbx} 5(\boldsymbol{C})$, ephrin-B1 (D), and ephrin-B2 $(\boldsymbol{E})$ was reduced, whereas that of Ventroptin $(\boldsymbol{F}), \operatorname{Vax}(\boldsymbol{G})$, EphB2 $(\boldsymbol{H})$, and $E p h B 3(\boldsymbol{I})$ was upregulated and expanded in the retina.

Bank accession number AF227921), and the 1185 bp fragment of mouse BMP2 (nucleotide residues 161-1345; GenBank accession number NM_007553). The templates for the probe of BMP2, BMP4, Ventroptin, cVax, Tbx5, ephrin-A2, ephrin-A5, EphA3, FoxG1, FoxD1, SOHo1 (sensory organ homeobox protein 1), and GH6 (Gallus gallus homeobox protein 6) have been described previously (Sakuta et al., 2001; Takahashi et al., 2003). Images were acquired using the Axioplan 2 microscope system (Zeiss, Oberkochen, Germany) or a CCD camera (CoolSNAP cf Color; Roper Scientific, Tucson, AZ).

Immunohistochemistry. Viral gag protein was visualized by immunostaining with the monoclonal antibody $3 \mathrm{C} 2$ as described previously (Yuasa et al., 1996). The ephrin-A2 protein was visualized by immunofluorescence method with a monoclonal antibody against chick ephrin-A2 (Ohta et al., 1996). Tissue sections were incubated for $60 \mathrm{~min}$ 
Control Side Experimental Side

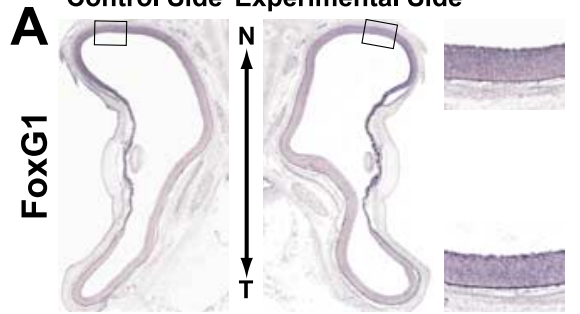

B

Control Side Experimental Side

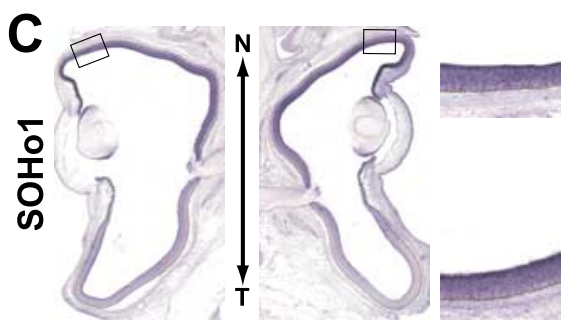

E
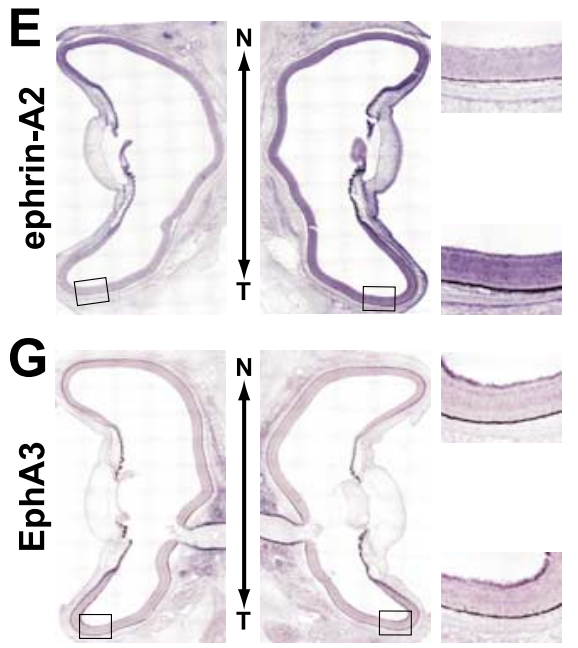
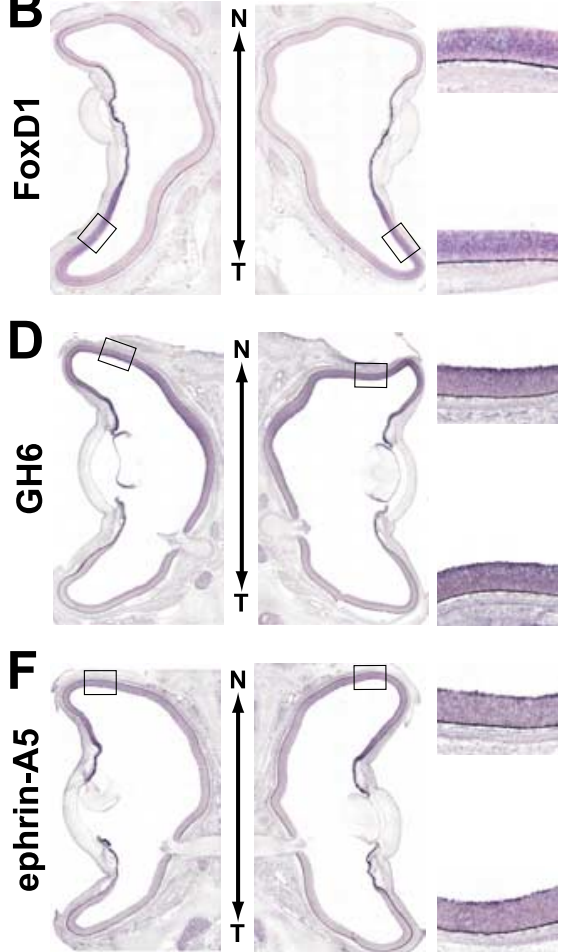

\begin{tabular}{|c|c|c|c|}
\hline \multicolumn{4}{|c|}{ Effect of BMP2 knockdown } \\
\hline Tbx2 & $\downarrow$ & FoxG1 & $\rightarrow$ \\
\hline Tbx3 & $\downarrow$ & FoxD1 & $\rightarrow$ \\
\hline Tbx5 & $\downarrow$ & SOHo1 & $\rightarrow$ \\
\hline ephrin-B1 & $\downarrow$ & GH6 & $\rightarrow$ \\
\hline ephrin-B2 & $\downarrow$ & ephrin-A2 & $\uparrow$ \\
\hline Ventroptin & $\uparrow$ & ephrin-A5 & $\rightarrow$ \\
\hline $\mathrm{cVax}$ & $\uparrow$ & EphA3 & $\rightarrow$ \\
\hline EphB2 & $\uparrow$ & & \\
\hline EphB3 & & & \\
\hline
\end{tabular}

Figure 3. The effect of BMP2 knockdown on the expression of topographic molecules along the N-T axis. A horizontal section in situ hybridization of control retinas (left) and RCASDC-CU6/BMP2-electroporated retinas (right) of E8 embryos is shown. The expression of FoxG1 $(\boldsymbol{A})$, FoxD1 (B), SOHo1 ( $)$, GH6 (D), ephrin-A5 (F), and EphA3 (G) was not changed. In contrast, the expression of ephrin-A2 (E) was induced all over the retina. The results of BMP2 knockdown in this and Figure 2 are summarized in $\boldsymbol{H}$.

in $0.3 \% \mathrm{H}_{2} \mathrm{O}_{2} /$ methanol. After washing in PBS, the sections were blocked for $90 \mathrm{~min}$ and incubated overnight with anti-ephrin-A2 monoclonal antibody at $4^{\circ} \mathrm{C}$. After washing, the sections were incubated overnight with horseradish peroxidase-conjugated secondary anti-mouse IgG antibody at $4^{\circ} \mathrm{C}$. Enhanced fluorescence was achieved with the Alexa-594tyramide signal amplification kit (Invitrogen) according to the instructions of the manufacturer.

Retinal axon tracing in the chick embryos. For retinal axon tracing, we labeled a small number of the retinal fibers with $1,1^{\prime}$-dioctadecyl$3,3,3^{\prime}, 3^{\prime}$-tetramethyl-indocarbocyanine perchlorate (DiI) (Invitrogen) at E14.5-E15.5 as described previously (Yuasa et al., 1996). Embryos were incubated for an additional $2 \mathrm{~d}$ to allow DiI to label retinal fibers from the retina to the tectum. Tecta were cut into lateral and medial halves and then observed using the Axioplan 2 microscope system.

\section{Results}

BMP2-specific knockdown by the vector-based shRNA

We recently demonstrated that misexpression of Ventroptin, a BMP antagonist, in the developing chick retina altered the retinotectal projection not only along the $\mathrm{M}-\mathrm{L}$ axis but also along the A-P axis (Sakuta et al., 2001). In that study, we could not discriminate the roles between BMP4 and BMP2, because Ventroptin antagonizes both of them. It is methodologically difficult to distinguish their functions using classical misexpression experi- ments, because BMP2 and BMP4 have almost the same biological activities (Padgett et al., 1993) and a certain level of $\mathrm{BMP}$ signal is essential for the retinal neurogenesis itself (Murali et al., 2005). To overcome this obstacle, we attempted to selectively knock down BMP2 using a vector-based shRNA that produces the RNA interference (RNAi) effect (Brummelkamp et al., 2002; Paddison et al., 2002; Yu et al., 2002). First, we performed a reporter assay to estimate the RNAi effect of the vector-based shRNA in chick cells (Fig. 1A). To quantify the RNAi effect of the vector-based shRNA, we ligated the coding region of either $B M P 2$ or $B M P 4$ downstream of the coding region of the firefly luciferase in the pCS2+luc vector to generate an mRNA with both sequences. When the expression plasmid for BMP2specific shRNA (SLAX-CU6/BMP2) was cotransfected with a reporter construct into CEFs, luciferase activity was greatly reduced with pCS2+luc/BMP2 but not with pCS2+luc/BMP4 (Fig. 1A). These results indicate that the RNAi effect of the SLAXCU6/BMP2 vector acts selectively on BMP2.

To test the RNAi effect of the vectorbased shRNA in vivo, we generated an RCAS vector with a unique restriction site in the $\mathrm{U} 3$ region of the $3^{\prime}$ LTR to insert the shRNA-expressing cassette (Fig. $1 B$ ). The provirus produced from the RCASDC vector acquires two copies of the shRNAexpressing cassette because of the duplication of the LTR at both ends during reverse transcription, and twofold expression of shRNA is expected in the chick embryos. When RCASDC-CU6/BMP2 was introduced into the right retina at E1.5 by in ovo electroporation, the whole area of the right retina was infected at E8, as was evident from the expression of gag protein (Fig. 1C). Under these conditions, BMP2 expression was markedly reduced at E8 (Fig. 1D, 17 of 24 embryos), although the degree of the reduction varied to some extent in individual embryos. In contrast, $B M P 4$ expression was not affected at all, at $\mathrm{E} 4$ when the expression peaked (Fig. 1E, 11 of 11 ) and at E8 when the expression was almost absent (data not shown). These results indicate that the RNAi effect of the SLAXCU6/BMP2 vector is faithfully selective against BMP2 also in vivo. In the retinas transfected with RCASDC/CU6-EGFP carrying an shRNA-expressing cassette against EGFP, the BMP2 expression was not altered (Fig. 1F, 10 of 10).

\section{Effects of BMP2 knockdown on the expression patterns of topographic molecules}

We next examined the effects of $B M P 2$ knockdown on the expression pattern of a panel of topographic molecules at E8 (Figs. 2, 3). In the $B M P 2$ knockdown eyes, the expression of the dorsal-high molecules Tbx2 (Fig. 2A, 12 of 17), Tbx3 (Fig. $2 B, 9$ of 12), Tbx5 (Fig. 2C, 7 of 11), ephrin-B1 (Fig. 2D, 10 of 15), and ephrin-B2 (Fig. $2 E, 6$ of 10) was markedly reduced, and the expression domain of the ventral-rich molecules Ventroptin (Fig. 2F, 10 of 19), 
cVax (Fig. 2G, 6 of 14), EphB2 (Fig. $2 H, 6$ of 10), and EphB3 (Fig. 2I, 5 of 11) was significantly expanded. Surprisingly, the expression of ephrin-A2 was also enhanced (Fig. 3E, 8 of 17). The degree of alterations correlated well with the extent of reduction in BMP2 expression (data not shown). At E4, the expression patterns of these molecules were unaffected in the BMP2 knockdown retina (data not shown), probably because the expression of $B M P 4$ was not affected at all and BMP2 expression is not detected in the retina at E4. In contrast to the molecules mentioned above, expression of FoxG1, FoxD1, SOHo1, GH6, EphA3, or ephrin-A5 (topographic molecules along A-P axis) was not significantly affected in the BMP2 knockdown eyes (Fig. 3). These results of in situ hybridization were all verified by quantification of the signal intensity using NIH Image J (supplemental Figs. 1, 2, available at www.jneurosci.org as supplemental material). In the retinas transfected with RCASDC/CU6-EGFP, the expression pattern of all of the topographic molecules tested was unaltered (data not shown). These results indicate that all the topographic molecules along the $\mathrm{D}-\mathrm{V}$ axis and ephrin-A2 along the A-P axis are located downstream of the BMP2 signal (Fig. $3 H$ ).

\section{Effects of BMP2 misexpression induced by DOX at later} stages on the expression pattern of topographic molecules With the decline in BMP4 expression from the dorsal retina, $B M P 2$ begins to be expressed in the developing retina from E5 (Takahashi et al., 2003). To manipulate the expression of a gene temporally during development, an inducible system with some reagent is essential. We took advantage of the tet regulatory system, in that the expression of a transgene can be activated by tetracycline or an analog thereof such as DOX (Gossen and Bujard, 1992; Gossen et al., 1995), to misexpress BMP2 in the retina only at the later stages (Fig. 4). For this purpose, we prepared two vectors (Fig. $4 A$ ). The TRE-mediated transgene expression depends on the expression level of $r t T A$ (Kistner et al., 1996). We used the RCASDC vector for driving $r t T A$, because a higher level of the transgene was detected in CEFs with RCASDC than RCAS, when the transgene was inserted into the ClaI site (data not shown). To examine whether the tet regulatory system functions in the chick retina, we simultaneously introduced RCASDC/rtTA and RCAN-TRE/EGFP harboring the EGFP gene into the chick retina by in ovo electroporation. DOX was administered twice to the embryos at E5 and E6.5, and the retinas were removed at E8. Many cells harboring EGFP fluorescence were observed in the presence of DOX (Fig. $4 \mathrm{~B}$ ). In contrast, only a few cells expressing EGFP were observed in the absence of DOX. These results indicate that the tet regulatory system works in the developing chick retina.

Next, we examined the effect of BMP2 misexpression induced by DOX on the expression patterns of the topographic molecules using this system (Figs. 5, 6). After DOX treatment following coelectroporation of RCASDC/rtTA and RCAN-TRE/BMP2, many of retinal cells began to express mouse BMP2 transcript
B

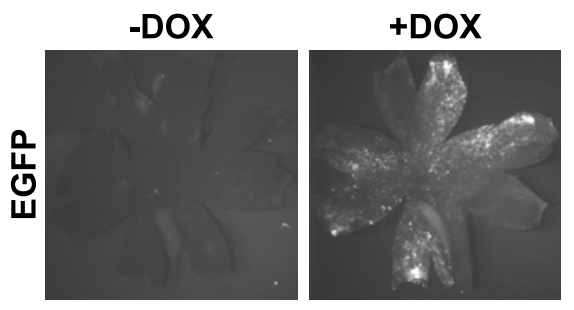

D

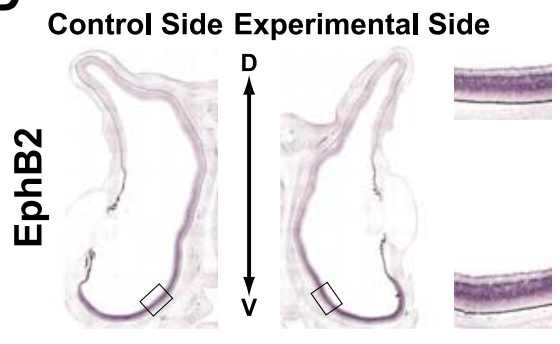

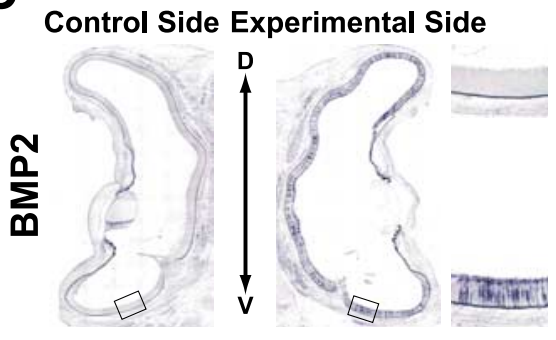

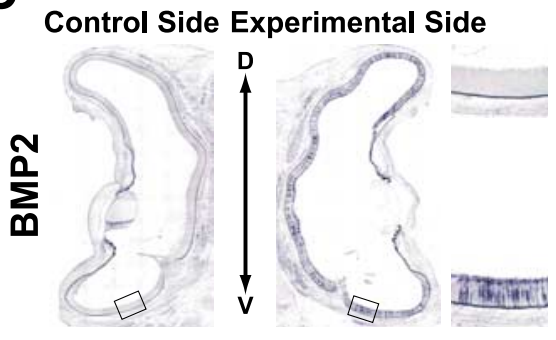

Figure 4. The reagent-inducible gene expression system for the chick. $A$, Schematic representation of the RCASDC/rtTA vector and RCAN-TRE vector. SD, Splicing donor; SA, splicing acceptor; $\mathrm{mCMV}$, minimal cytomegalovirus promoter. $\boldsymbol{B}$, EGFP expression in 1.5. EAS of E8 embryos with/without DOX treatment. RCASDC/rtTA and RCAN-TRE/EGFP were simultaneously electroporated at 政 not changed without DOX treatment (D). The boxed regions in the control retina (left) and manipulated retina (right) are enlarged on the top right and bottom right sides, respectively.

throughout the right retina (Fig. 4C). In these embryos, the expression of the dorsal-high molecules was upregulated and that of the ventral-high molecules was downregulated in the retina by $B M P 2$ misexpression (Fig. 5): Tbx2 (Fig. 5A, 6 of 11), Tbx3 (Fig. $5 B, 11$ of 20), Tbx5 (Fig. 5C, 6 of 14), ephrin-B1 (Fig. 5D, 6 of 10), ephrin-B2 (Fig. 5E, 6 of 13), Ventroptin (Fig. 5F, 10 of 14), cVax (Fig. 5G, 7 of 10), EphB2 (Fig. 5H, 11 of 15), EphB3 (Fig. 5I, 6 of 10 ), and ephrin-A2 (Fig. 6E, 12 of 20). This is the reverse of the pattern after $B M P 2$ knockdown. The expression pattern of these genes did not change when $B M P 2$ was not induced without DOX treatment (Fig. $4 D$ and data not shown). As in the case of BMP2 knockdown, $B M P 2$ misexpression at later stages did not alter the expression of FoxG1, FoxD1, SOHo1, GH6, EphA3, or ephrin-A5 (Fig. 6). These results further support the view that all of the topographic molecules along the $\mathrm{D}-\mathrm{V}$ axis and ephrin- $\mathrm{A} 2$ are all controlled by BMP2 (Fig. $6 \mathrm{H}$ ). Quantifications of these results are shown in supplemental Figures 3 and 4 (available at www.jneurosci.org as supplemental material).

\section{Oblique-gradient molecules in the retina}

It is known that the counteraction between BMP4 and Ventroptin along the $\mathrm{D}-\mathrm{V}$ axis is switched by that between $B M P 2$ and Ventroptin along the $\mathrm{D} / \mathrm{T}-\mathrm{V} / \mathrm{N}$ axis from $\mathrm{E} 5$. We therefore presumed that the expression of the topographic molecules controlled by $B M P 2$ are also changed to the oblique-gradient pattern in the retina like Ventroptin and BMP2. So we examined the expression pattern of a panel of topographic molecules in the chick retina at E8.

Three T-box transcription factors, $T b \times 2, T b \times 3$, and $T b \times 5$, are expressed in the dorsal chick retina during the early stages $(\mathrm{HH}$ stage 14) of the development of the eye (Gibson-Brown et al., 1998) and contribute to retinal patterning and the formation of the retinotectal map (Koshiba-Takeuchi et al., 2000; Wong et al., 2002; Gross and Dowling, 2005). We found that these transcrip- 


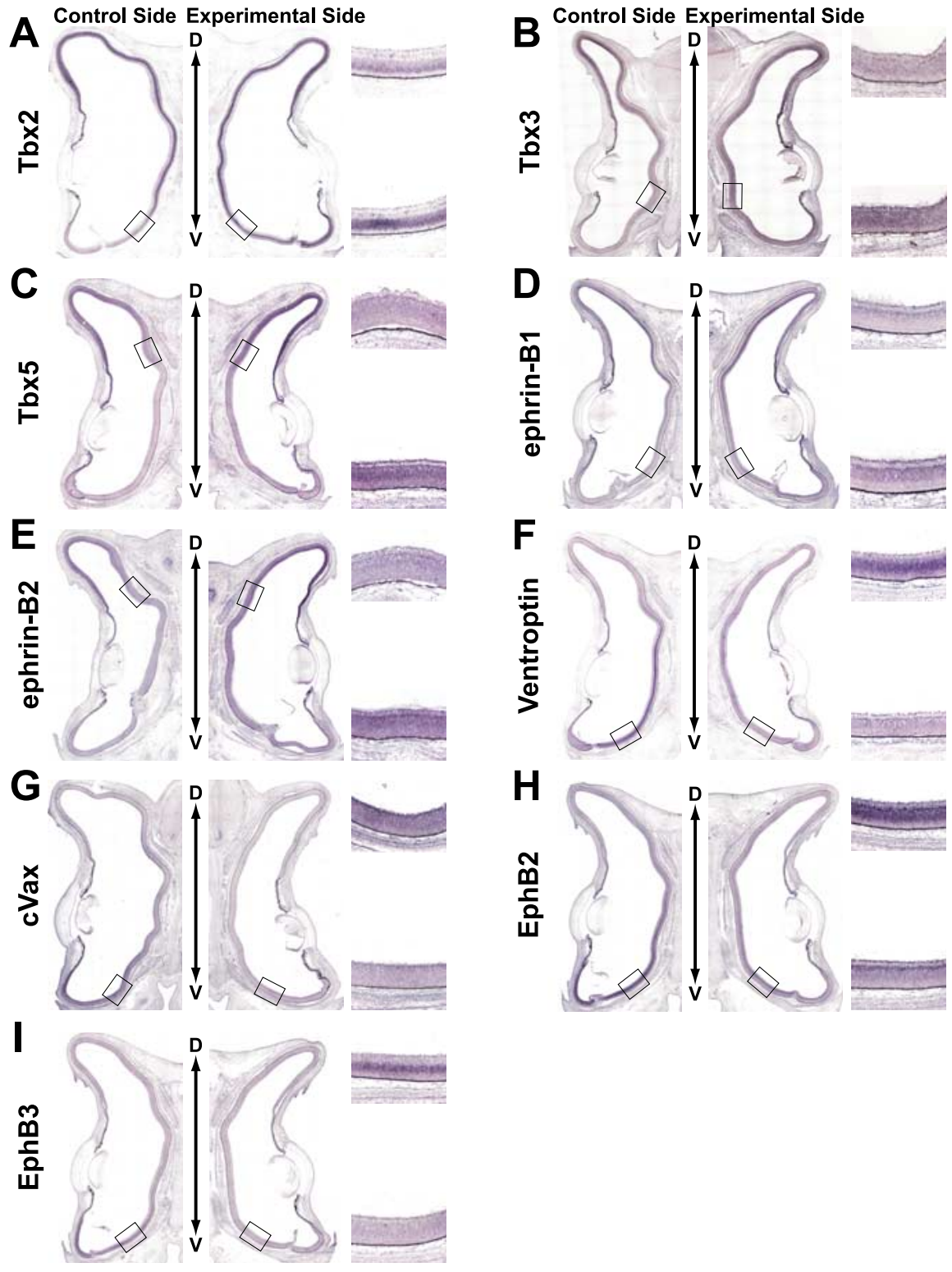

Figure 5. The effect of BMP2 misexpression on the expression of topographic molecules along the $D-V$ axis. Coronal section in situ hybridization of the retinas of E8 embryos after DOX treatment is shown. RCASDC/rtTA and RCAN-TRE/BMP2 were simultaneously electroporated at E1.5. Control retinas and transfected retinas are shown on the left and right, respectively. Boxed regions were selected at the ventral limit with the expression of the topographic molecules in the control retina $(\boldsymbol{A}-\boldsymbol{E})$ and the ventral retina $(\boldsymbol{F}-\boldsymbol{I})$ to show the alteration by the manipulation. The expression of $\operatorname{Tbx2}(\boldsymbol{A}), \operatorname{Tbx3}(\boldsymbol{B}), \operatorname{Tbx} 5(\boldsymbol{C})$, ephrin-B1 $(\boldsymbol{D})$, and ephrin-B2 $(\boldsymbol{E})$ was upregulated and expanded in the retina, whereas that of Ventroptin $(\boldsymbol{F}), \operatorname{Cax}(\boldsymbol{G}), \operatorname{EphB2}(\boldsymbol{H})$, and EphB3 $(\boldsymbol{I})$ was downregulated.

tion factors were expressed in the E8 retina with dorsal-high ventral-low and temporal-high nasal-low gradients (D/T-high pattern) (Fig. $7 B-D$ ) like $B M P 2$ (Fig. $7 A$ ). The expression patterns of these T-box genes were similar, but the expression domain of $T b \times 2$ was the widest and that of $T b \times 5$ was the narrowest. The Emx (empty spiracles homolog) homeobox gene $c V a x$ is also implicated in the D-V patterning in the retina (Schulte et al., 1999). It was found to be expressed in a complementary obliquegradient pattern (V/N-high pattern) at E8 (Fig. $8 \mathrm{~B}$ ) like Ventroptin (Fig. $8 A$ ). This expression pattern is similar to that of Vax2 in the mouse retina (Mui et al., 2002). EphB2/B3 and their ligands ephrin-B1/B2 are known to be expressed in the ventral and dorsal retina, respectively, early on and involved in the retinotectal mapping along the M-L axis (Hindges et al., 2002; Mann et al., 2002;
McLaughlin et al., 2003b). However, ephrin-B1/B2 (Fig. 7 E, F) and EphB2/B3 (Fig. $8 C, D)$ also showed an oblique-gradient expression (D/T-high and V/N-high patterns, respectively) at E8. Flat-mount in situ hybridization of E5 and E8 retinas clearly indicates that the expression of ephrin-B1 and EphB2 show a obliquegradient pattern at $\mathrm{E} 8$ as the result of the tilting of the D-V axis (supplemental Fig. 5, available at www.jneurosci.org as supplemental material).

The ligands of EphA receptors, ephrin-A2 and ephrin-A5, have been reported to be expressed in the nasal retina and control the retinotectal projection along the A-P axis by modulating EphA receptor function (Dütting et al., 1999; Hornberger et al., 1999). Ephrin-A2, but not ephrin-A5, was found to be expressed with a V/N-high oblique-gradient at E8 (Fig. $8 E, F)$. Notably, the gradient of ephrin-A2 along the $\mathrm{D}-\mathrm{V}$ axis was relatively small compared with that of any of the other oblique-gradient molecules. The oblique-gradient molecules are summarized in Figure 8G. Importantly, no gradient along the $\mathrm{D}-\mathrm{V}$ axis could be detected in the expression patterns of FoxG1, FoxD1, SOHo1, GH6, and EphA3 (data not shown), which are not under the control of BMP2 signal and asymmetrically distributed only along the A-P axis (Yuasa et al., 1996; Connor et al., 1998; Schulte and Cepko, 2000).

\section{Retinotectal projections in BMP2 knockdown and ephrin-A2-misexpressed embryos}

The most faithful readout of retinal patterning is the pattern of the retinotectal map. Because BMP2 thus appears to be a key regulator of retinal patterning along both the D-V and A-P axes, we next analyzed the retinotectal projection in the BMP2 knockdown embryos at E16.5E17.5, when the retinotectal projection map is completed in the chick (Nakamura and O'Leary, 1989). To observe the behavior of the retinal ganglion cell axons, we labeled a small number of the dorsotemporal retinal axons with DiI (Fig. 9A), in which BMP2 is most abundant in the normal retina. In the control embryos electroporated only with RCASDC/CU6-EGFP, the dorsotemporal axons formed a tight terminal zone near the anterior end of the lateral tectum (Fig. 9B, C, 10 of 10). In BMP2 knockdown embryos, in contrast, the dorsotemporal axons did not form a tight terminal zone at the proper position (Fig. 9D, E, asterisk): their trajectories shifted to the medial side of the lateral tectum (Fig. 9D, small arrows, 7 of 12), and some axons projected to the medial tectum (Fig. 9D, large arrows). These results indicate that the dorsotemporal axons in $B M P 2$ knockdown embryos showed the profile of the central or ventronasal axons. Quantifications of these results along the A-P and M-L axes are shown in 
supplemental Figure 6 (available at www. jneurosci.org as supplemental material). Importantly, similar to the Ventroptinmisexpressed embryos (Sakuta et al., 2001), these axons overshot the proper position along the A-P axis, although none of them reached to the posterior end (Fig. $9 D$, arrowheads). In contrast to the dorsotemporal axons, the ventronasal axons projected to the proper place (data not shown) (11 of 11). This is probably because $B M P 2$ was not expressed in the ventronasal retina (Fig. 7A). Actually, the expression of the topographic molecules was not affected in the BMP2 knockdown embryos, when it was restricted to the ventronasal area (Fig. 2).

We presumed that $B M P 2$ controls the retinotectal projection along both axes by regulating the expression of the downstream oblique-gradient molecules, including ephrin-A2. We next misexpressed ephrin-A2 in the developing chick retina to verify that the retinotectal projection is altered along both axes. When RCAS/ ephrin-A2 was introduced into the retina by electroporation, the ephrin-A2 protein was detected throughout the transfected retina at E8 (Fig. 9F). In the ephrin-A2misexpressing embryos, expected projection errors were found with a high incidence (Fig. 9G,H, 9 of 12 embryos). In most cases (six of nine), the dorsotemporal axons did not form a tight terminal zone at the proper position (Fig. 9G, asterisk), and most of them overshot the locus (Fig. 9G, arrowheads). Furthermore, notably, their trajectories shifted to the medial side in the lateral tectum (Fig. 9G, small arrows). These results indicate that the dorsotemporal axons in the ephrinA2-misexpressing embryos showed the profile of the central or ventronasal axons. In contrast to the dorsotemporal axons, the ventronasal axons did not make any significant targeting errors (data not shown) (seven of seven): this is probably because the expression of ephrin- $A 2$ is the most abundant in the ventronasal retina (Fig. $8 E$ ), and the overexpression of ephrin-A2 did not exert any additional effect. Quantifications of the results are shown in supplemental Figure 6 (available at www.jneurosci.org as supplemental material).

\section{Discussion}

Retinal patterning along the two axes and subsequent topographic retinotectal projection are thought to be controlled and established by a series of gene cascades expressed in a regionspecific manner in the developing retina. In the present study, we revealed that the topographic molecules along the $\mathrm{D}-\mathrm{V}$ axis in the chick retina are under the control of BMP4 and then BMP2 during development. The axis along the fissure has been defined as the $\mathrm{D}-\mathrm{V}$ axis early on in development, but the $\mathrm{D}-\mathrm{V}$ axis is tilted to the posterior side at approximately E5 through the switch from $B M P 4$ to $B M P 2$, along with the corresponding change in the expression pattern of the downstream topographic molecules:
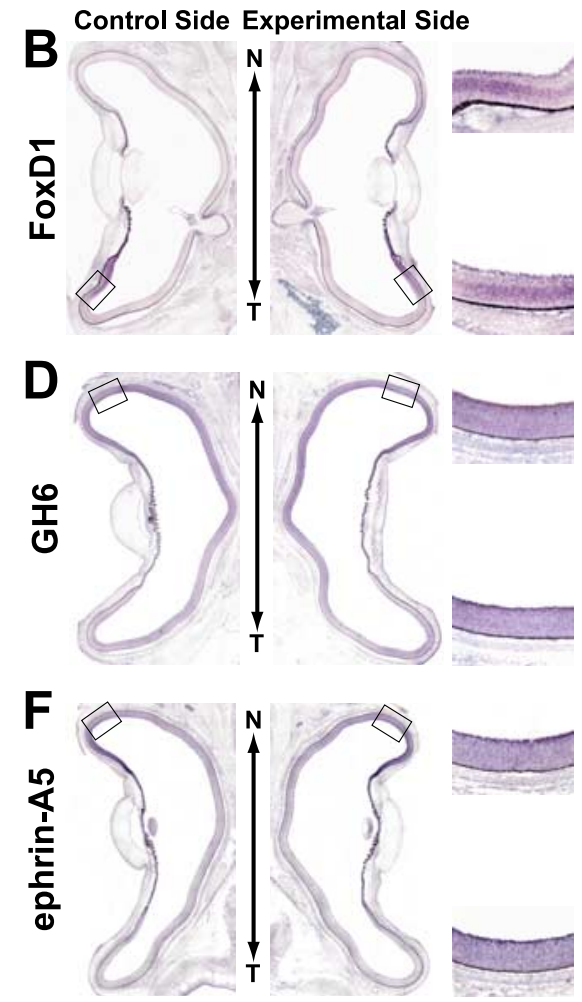

\begin{tabular}{|c|c|c|c|}
\hline \multicolumn{4}{|c|}{ Effect of $B M P 2$ misexpression } \\
\hline Tbx2 & $\bar{\uparrow}$ & FoxG1 & $\rightarrow$ \\
\hline Tbx3 & $\uparrow$ & FoxD1 & $\rightarrow$ \\
\hline Tbx5 & $\uparrow$ & SOHo1 & $\rightarrow$ \\
\hline ephrin-B1 & $\uparrow$ & $\mathrm{GH} 6$ & $\rightarrow$ \\
\hline ephrin-B2 & $\uparrow$ & ephrin-A2 & $\downarrow$ \\
\hline Ventroptin & $\downarrow$ & ephrin-A5 & $\rightarrow$ \\
\hline cVax & $\downarrow$ & EphA3 & $\rightarrow$ \\
\hline EphB2 & $\downarrow$ & & \\
\hline EphB3 & $\downarrow$ & & \\
\hline
\end{tabular}
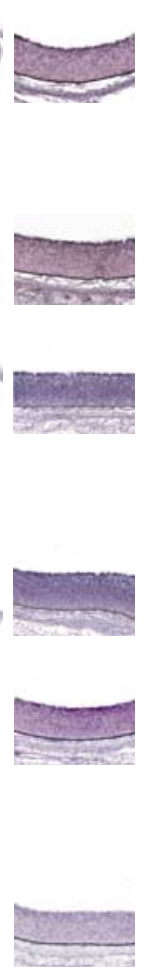

Control Side Experimental Side

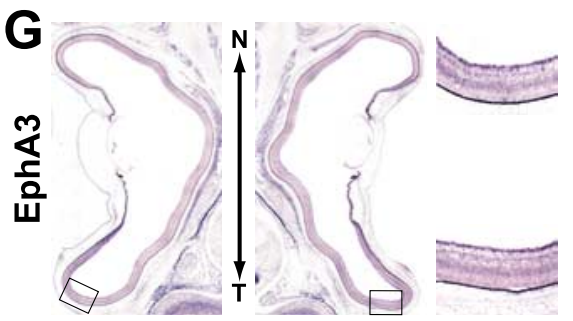

Figure 6. The effect of BMP2 misexpression on the expression of topographic molecules along the N-T axis. In situ hybridization taneously electroporated at E1.5. Control retinas and transfected retinas are shown on the left and right, respectively. Expression of FoxG1 (A), FoxD1 (B), SOHo1 (C), GH6 (D), ephrin-A5 (F), and EphA3 (G) was not changed. In contrast, ephrin-A2 (E) was downregulated by BMP2 misexpression. The results of $B M P 2$ misexpression in this and Figure 5 are summarized in $\boldsymbol{H}$.

the revised oblique $\mathrm{D}-\mathrm{V}$ axis $(\mathrm{D} / \mathrm{T}-\mathrm{V} / \mathrm{N}$ axis) is not perpendicular to the A-P axis anymore from E6 onward, when retinal axons begin to project to the tectum in chick embryos. In addition, we found that ephrin-A2 is also under the control of $B M P 2$, and its expression begins from E6 with a gradient along the D/T-V/N axis in a V/N-high pattern (Takahashi et al., 2003). When the expression of $B M P 2$ or ephrin-A2 was manipulated in the developing retina by knockdown or misexpression, the retinotectal projection was expectedly altered along the two axes.

The presence of oblique-gradient molecules in the retina was not recognized until our discovery of Ventroptin (Sakuta et al., 2001). This presumably happened because previous studies of retinal patterning and retinotectal projection focused on only either the A-P or the $\mathrm{D}-\mathrm{V}$ axis individually. However, the oblique-gradient expression appears not to be specific to the chick, because mouse Vax2 was also reported to be expressed in a oblique-gradient (V/N-high) pattern in the retina (Mui et al., 2002). We now know that many known and unknown topographic molecules show a oblique-gradient expression pattern at E8 (Fig. 8G) (Shintani et al., 2004). These include the topographic molecules that were thought to be differentially expressed along 
A

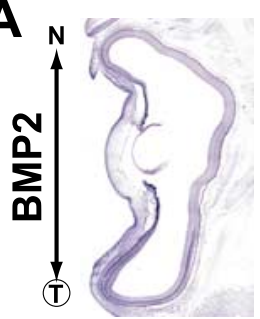

C

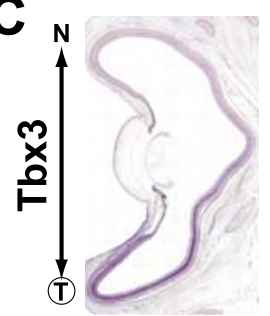

E

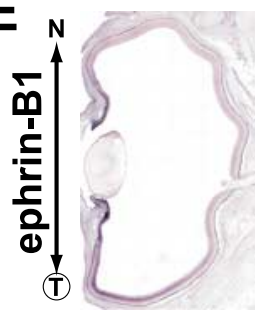

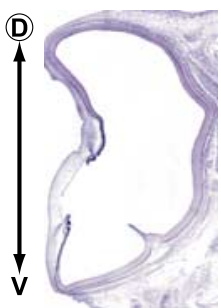
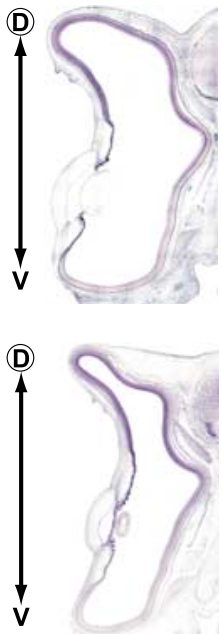

B

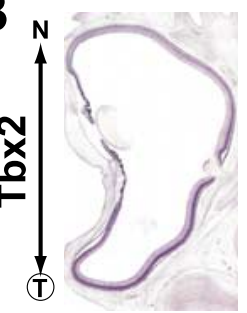

D
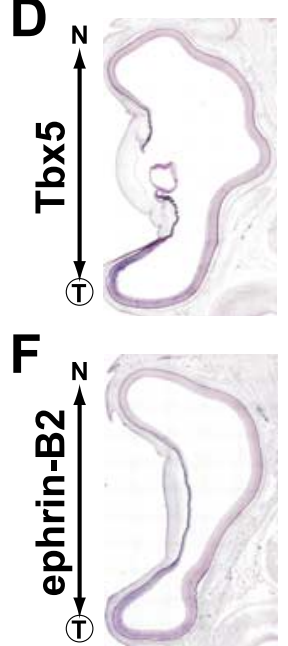

Figure 7. Identification of oblique-gradient molecules in the chick retina. In situ hybridization of horizontal (left) and coronal (right) sections of E8 retinas. BMP2 (A), Tbx2 (B), Tbx3 $(\boldsymbol{C}), T b \times 5(\boldsymbol{D})$, ephrin-B1 (E), and ephrin-B2 $(\boldsymbol{F})$ show a dorsotemporal-high expression. The higher side along the $\mathrm{N}-\mathrm{T}$ and $\mathrm{D}-\mathrm{V}$ axes was encircled.

the D-V axis and ephrin-A2 that was thought to be expressed along the A-P axis in a nasal-high pattern. Phenotypic defects in the topographic mapping along the M-L axis are often accompanied by those along the A-P axis and vice versa [for the phenotypic defects caused by altering the expression of individual topographic genes, see review by McLaughlin et al. (2003a)]. We can now understand the reason. The fact that the revised $\mathrm{D}-\mathrm{V}$ axis is not perpendicular to the A-P axis should be the reason why misexpression or knockdown of the topographic molecules along the revised $\mathrm{D}-\mathrm{V}$ axis induces alteration in the topographic mapping along the two axes in the tectum (or SC). In support of this view, ephrin-A2 and Ventroptin misexpression and BMP2 knockdown in the developing retina indeed induced phenotypic defects in the topographic mapping along both axes (Fig. 9) (Sakuta et al., 2001). Hornberger et al. (1999) reported that retinal overexpression of ephrin-A2 leads to topographic errors among temporal axons. Consistent with our findings, according to our observation, the trajectories in the report appear to shift to the medial side of the tectum in addition to the defect along the A-P axis. Moreover, Chandrasekaran et al. (2005) recently reported that overexpression of BMP2 leads to topographic errors among ventral axons, lateral to their normal target zone, in the eye-specific transgenic mouse. Consistent with our findings, ventral axons in their report evidently mistarget in the SC along the A-P axis in addition to the M-L axis. Thus, the topographic molecules with the oblique-gradient expression probably control the topographic mapping along both axes. Here, it should be noted that tilting of the axis may not be a specific event in the retina, because ephrin-A2 and ephrin-A5 have been reported to be expressed in a oblique gradient in the tectum (SC) and lateral geniculate nucleus (Feldheim et al., 1998; Feldheim et al., 2000; Marín et al.,
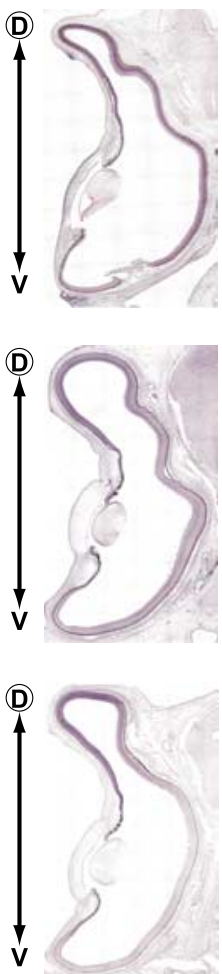

2001). This suggests the possibility that the axes in the retina and tectum are revised in a concerted manner during development.

We can now present gene cascades of topographic molecules for retinal patterning and retinotectal projection as in Figure 10. FoxG1 and FoxD1 are expressed in the nasal and temporal regions of the developing chick retina at an early stage (peaking at E3), respectively, and determine the regional specificity in the retina by their counteraction (Yuasa et al., 1996; Takahashi et al., 2003). Consequently, two homeobox transcription factors, $\mathrm{SOHo} 1$ and $G H 6$, are expressed specifically in the nasal region: it is known that the two control the retinotectal projection along the A-P axis by the repression of EphA3 expression (Schulte and Cepko, 2000). Afterward, ephrin-A5 and ephrin-A2 begin to show the nasal-high expression and EphA3 temporal-high expression in the retina. In this process, FoxG1 controls ephrin-A5 via a DNA binding-dependent mechanism, ephrin-A2 via a DNA bindingindependent mechanism, and FoxD1, SOHol, GH6, and EphA3 via dual mechanisms (Takahashi et al., 2003). Along the $\mathrm{D}-\mathrm{V}$ axis, counteraction between BMP4 and Ventroptin governs the regional specification in the retina: at the early stages of development from $\mathrm{HH}$ stage 11 to E5, dorsally expressed BMP4 determines the regional specificity of the dorsal retina (Koshiba-Takeuchi et al., 2000; Murali et al., 2005), and ventrally expressed Ventroptin counteracts the activity of BMP4 (Sakuta et al., 2001). At approximately E5, BMP4 expression in the dorsal retina rapidly disappears. Concomitantly, Ventroptin comes to be expressed in a oblique-gradient manner $(\mathrm{V} /$ $\mathrm{N}$-high pattern from E6 onward). Then, instead of BMP4, BMP2 begins to be expressed in a oblique-gradient manner (D/T-high pattern), complementary to that of Ventroptin to counteract it (Takahashi et al., 2003). In that, the inhibitory effect of FoxG1 on the BMP signaling is thought to be responsible for turning the expression patterns of Ventroptin and BMP2 $\sim 30^{\circ}$ to the posterior side from the first $\mathrm{D}-\mathrm{V}$ axis (Sakuta et al., 2001; Takahashi et al., 2003). Switching from $B M P 4$ to $B M P 2$ should occur because of the difference in their genetic regulatory mechanisms, and this would be the basis of the tilting of the $\mathrm{D}-\mathrm{V}$ axis in the developing retina. Because BMP2 and Ventroptin are located at the top of the hierarchy of the oblique-gradient molecules, they should control retinotectal projection most effectively along the two axes. This view was verified by our experimental results that the retinotectal projections were severely altered along both axes in the tectum of the Ventroptin-misexpressed embryos (Sakuta et al., 2001) and BMP2 knockdown embryos (Fig. 9D). Our results also indicate that the plasticity of the regional specificity along the first (orthogonal) and second (tilted) D-V axes are long maintained by BMP signaling and that BMP2 accepts responsibility for the maintenance of the second $\mathrm{D}-\mathrm{V}$ axis at the later stage in the retina. In $B M P 2$ knockdown embryos, BMP4 expression was almost negative after E6 as in the control embryo and was never upregulated at the later stages (data not shown). To maintain the D-V axis to be orthogonal to the A-P axis, it appears to be necessary to 
maintain the expression of $B M P$ with the dorsal-high pattern in the retina throughout later stages.

Tbx5 and cVax have dorsalizing and ventralizing activities in the retina, respectively (Schulte et al., 1999; KoshibaTakeuchi et al., 2000), counteracting each other similar to the relation between BMPs and Ventroptin (Sakuta et al., 2001; Takahashi et al., 2003). Although they are located downstream of BMPs and Ventroptin, their expression domains in the E8 retina have a gap of significant width in which neither of them is expressed (Figs. $7 D, 8 B) . T b \times 2$ and $T b \times 3$ are expressed with dorsal-high ventral-low and temporal-high nasal-low gradients, the same as $T b \times 5$ (Fig. $7 B, C$ ), but they cover the gap region. They are also involved in the $\mathrm{D}-\mathrm{V}$ and then $\mathrm{D} / \mathrm{T}-\mathrm{V} / \mathrm{N}$ patterning of the retina together with $T b x 5$ (Wong et al., 2002; Gross and Dowling, 2005). Because these transcription factors are also oblique-gradient molecules acting downstream of $B M P 2$, it is expected that they are also involved in the regulation of retinal patterning and retinotectal projection along both axes.

The establishment of retinal polarity is the basis for both the topographic expression of the axon guidance molecules and the formation of the retinotectal map as described above. In addition, it is also known that many retinal cells are topographically organized within the retina. For instance, chick retinal ganglion cells and rod photoreceptor cells show an asymmetric distribution along the $\mathrm{D}-\mathrm{V}$ and A-P axes (Chen and Naito, 1999; Schulte et al., 2005). The distribution of these cells in the retina is also thought to be determined by the topographic transcription factors. This view was supported by the observation that the $\mathrm{V} / \mathrm{N}$-rich distribution of rod photoreceptor cells is severely disturbed by the ectopic expression of $c \operatorname{Vax}$ and a dominantnegative form of Tbx5 (Schulte et al., 2005). Cone cells are also asymmetrically distributed along both the D-V and A-P axes in the mouse retina but only along the $\mathrm{D}-\mathrm{V}$ axis in the rabbit retina (Szél et al., 1992; Juliusson et al., 1994). The distribution of photoreceptor cells is organized in a region-specific manner but differently among the vertebrate species (Waldvogel, 1990; Cepko, 1996; Ahnelt and Kolb, 2000; Peters, 2002). This appears to be the result of adaptations to the lifestyle of each species during evolution and must be precisely controlled by a set of genes during development. Although additional studies are necessary, the degree of inclination of the $\mathrm{D}-\mathrm{V}$ axis may vary between species to generate a species-specific distribution of the retinal neuronal species.

\section{References}

Ahnelt PK, Kolb H (2000) The mammalian photoreceptor mosaic-adaptive design. Prog Retin Eye Res 19:711-777. 7 are summarized in $\boldsymbol{G}$.
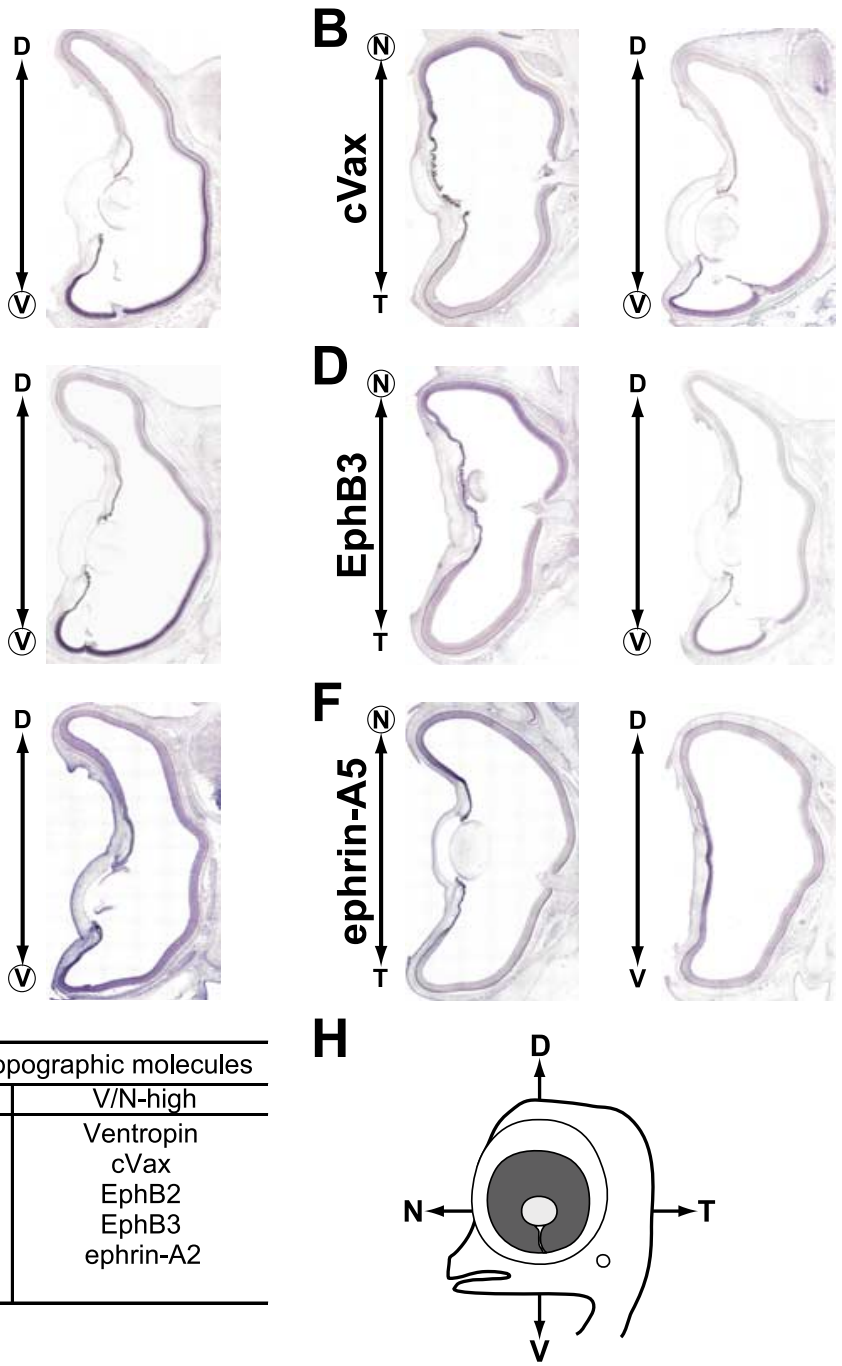

Figure 8. Identification of oblique-gradient molecules in the chick retina. In situ hybridization of horizontal (left) and coronal (right) sections of E8 retinas. Ventroptin $(\boldsymbol{A}), C \operatorname{Vax}(\boldsymbol{B}), E p h B 2(\boldsymbol{C}), E p h B 3(\boldsymbol{D})$, and ephrin-A2 (E) show a ventronasal-high expression. In contrast, the expression of ephrin- $A 5(\boldsymbol{F})$ has a simple nasal-high pattern. Oblique-gradient molecules shown in this and Figure

Aiyar A, Hindmarsh P, Skalka AM, Leis J (1996) Concerted integration of linear retroviral DNA by the avian sarcoma virus integrase in vitro: dependence on both long terminal repeat termini. J Virol 70:3571-3580.

Brown A, Yates PA, Burrola P, Ortuno D, Vaidya A, Jessell TM, Pfaff SL, O'Leary DD, Lemke G (2000) Topographic mapping from the retina to the midbrain is controlled by relative but not absolute levels of EphA receptor signaling. Cell 102:77-88.

Brummelkamp TR, Bernards R, Agami R (2002) A system for stable expression of short interfering RNAs in mammalian cells. Science 296:550-553.

Cepko CL (1996) The patterning and onset of opsin expression in vertebrate retinae. Curr Opin Neurobiol 6:542-546.

Chandrasekaran AR, Plas DT, Gonzalez E, Crair MC (2005) Evidence for an instructive role of retinal activity in retinotopic map refinement in the superior colliculus of the mouse. J Neurosci 25:6929-6938.

Chen Y, Naito J (1999) A quantitative analysis of cells in the ganglion cell layer of the chick retina. Brain Behav Evol 53:75-86.

Connor RJ, Menzel P, Pasquale EB (1998) Expression and tyrosine phosphorylation of Eph receptors suggest multiple mechanisms in patterning of the visual system. Dev Biol 193:21-35.

Dütting D, Handwerker C, Drescher U (1999) Topographic targeting and pathfinding errors of retinal axons following overexpression of ephrin A ligands on retinal ganglion cell axons. Dev Biol 216:297-311.

Feldheim DA, Vanderhaeghen P, Hansen MJ, Frisén J, Lu Q, Barbacid M, Flanagan JG (1998) Topographic guidance labels in a sensory projection to the forebrain. Neuron 21:1303-1313. 
A
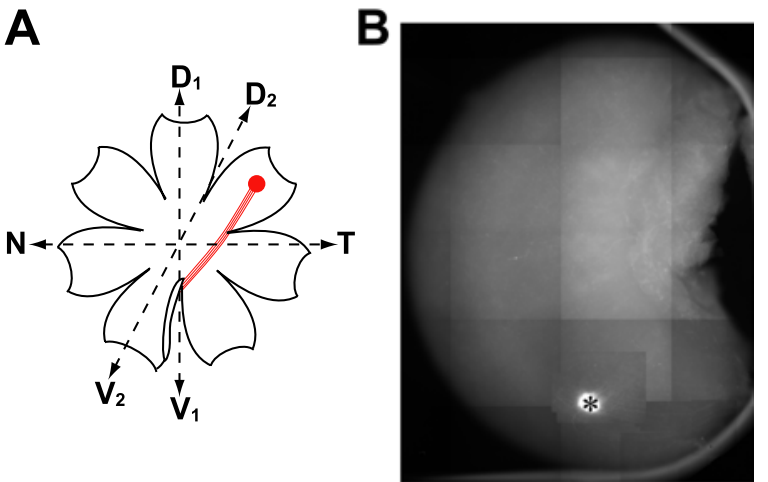

D

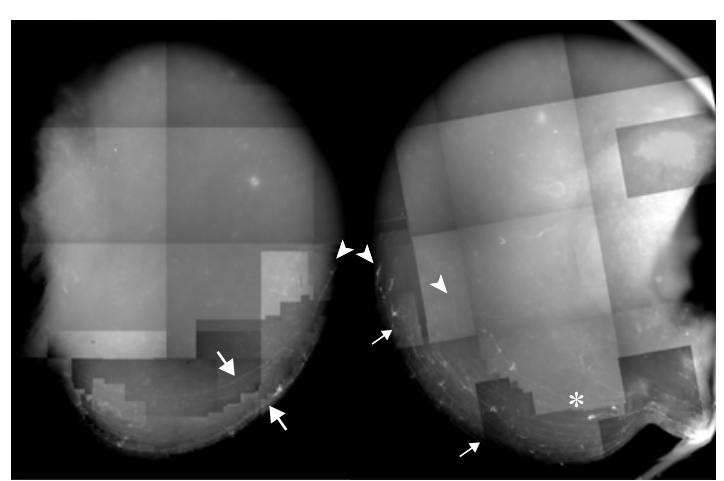

$F$
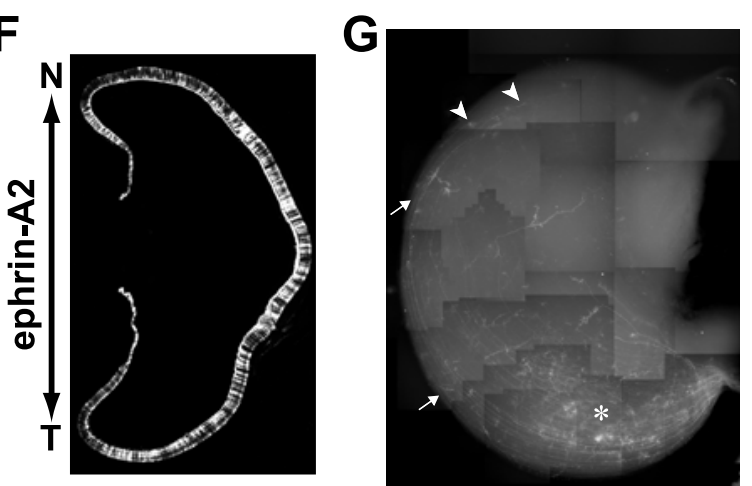

Figure 9. Retinotectal projection in BMP2 knockdown and ephrin-A2-misexpressed embryos. In the control embryo, retinal ganglion cell axons emanating from the nasal (anterior) retina project to the posterior tectum, whereas those from the temporal (posterior) retina project to the anterior tectum. Likewise, axons from the dorsal retina project to the lateral (ventral) tectum, whereas those from the ventral retina project to the medial (dorsal) tectum. $A$, Position of the Dil label in the dorsotemporal periphery of the right retina: the second $D-V$ $\left(D_{2}-V_{2}\right)$ axis is shown, together with the N-T (A-P) and the first D-V $\left(D_{1}-V_{1}\right)$ axes. $B, A$ typical projection pattern in the control RCASDCCU6/EGFP-transfected embryo at E16.5. The dorsotemporal axons form a tight terminal zone in the anterolateral region of the tectum (asterisk). D, A typical projection pattern in the BMP2 knockdown embryo at E16.5. Many dorsotemporal axons not only shifted to the medial side (small arrows) or extended on the medial tectum (large arrows) but also overshot their expected terminal zone (asterisk) along the A-Paxis (arrowheads). The mapping phenotype in the BMP2 knockdown embryos was thus consistent with but less severe than that in the Ventroptin-misexpressing embryos. This is probably explained by the incomplete loss of BMP2 expression in our knockdown experiments. $\boldsymbol{F}$, Expression of ephrin-A2 in the E8 retina by electroporation of RCAS/ephrin-A2. The ephrin-A2 protein was visualized by immunofluorescence with monoclonal antibody against chick ephrin-A2. The ephrin-A2 protein was expressed throughout the transfected eye. $\mathbf{G}$, A typical projection pattern in the ephrin-A2-misexpressing embryo at E16.5. Most dorsotemporal axons overshot their expected terminal zone (asterisk) along the A-P axis (arrowheads), and their trajectories shifted to the medial side (small arrows). $\boldsymbol{C}, \boldsymbol{E}, \boldsymbol{H}, \mathrm{Schematic}$ drawings of $\boldsymbol{B}, \boldsymbol{D}$, and $\boldsymbol{G}$, respectively. Anterior is down.

sion of T-box genes Tbx2-Tbx5 during chick organogenesis. Mech Dev 74:165-169.

Gossen M, Bujard H (1992) Tight control of gene expression in mammalian cells by tetracycline-responsive promoters. Proc Natl Acad Sci USA 89:5547-5551.

Gossen M, Freundlieb S, Bender G, Müller G, Hillen W, Bujard H (1995) Transcriptional activation by tetracyclines in mammalian cells. Science 268:1766-1769.

Gross JM, Dowling JE (2005) Tbx2b is essential for neuronal differentiation along the dorsal/ ventral axis of the zebrafish retina. Proc Natl Acad Sci USA 102:4371-4376.

Hantzopoulos PA, Sullenger BA, Ungers G, Gilboa E (1989) Improved gene expression upon transfer of the adenosine deaminase minigene outside the transcriptional unit of a retroviral vector. Proc Natl Acad Sci USA 86:3519-3523.

Hindges R, McLaughlin T, Genoud N, Henkemeyer M, O’Leary DD (2002) EphB forward signaling controls directional branch extension and arborization required for dorsal-ventral retinotopic mapping. Neuron 35:475-487.

Hornberger MR, Dütting D, Ciossek T, Yamada T, Handwerker C, Lang S, Weth F, Huf J, Wessel R, Logan C, Tanaka H, Drescher U (1999) Modulation of EphA receptor function by coexpressed ephrinA ligands on retinal ganglion cell axons. Neuron 22:731-742.

Hughes SH, Greenhouse JJ, Petropoulos CJ, Sutrave P (1987) Adaptor plasmids simplify the insertion of foreign DNA into helperindependent retroviral vectors. J Virol 61:3004-3012.

Juliusson B, Bergström A, Röhlich P, Ehinger B, van Veen T, Szél Á (1994) Complementary cone fields of the rabbit retina. Invest Ophthalmol Vis Sci 35:811-818.

Kistner A, Gossen M, Zimmermann F, Jerecic J, Ullmer C, Lübbert H, Bujard H (1996) Doxycycline-mediated quantitative and tissuespecific control of gene expression in transgenic mice. Proc Natl Acad Sci USA 93:10933-10938.

Koshiba-Takeuchi K, Takeuchi JK, Matsumoto K, Momose T, Uno K, Hoepker V, Ogura K, Takahashi N, Nakamura H, Yasuda K, Ogura T (2000) Tbx5 and the retinotectum projection. Science 287:134-137.

Mann F, Ray S, Harris W, Holt C (2002) Topographic mapping in dorsoventral axis of the $\mathrm{Xe}$ nopus retinotectal system depends on signaling through ephrin-B ligands. Neuron 35:461-473.

Marín O, Blanco MJ, Nieto MA (2001) Differential expression of Eph receptors and ephrins correlates with the formation of topographic projections in primary and secondary visual circuits of the embryonic chick forebrain. Dev Biol 234:289-303.

McLaughlin T, Hindges R, O’Leary DD (2003a) Regulation of axial patterning of the retina and its topographic mapping in the brain. Curr Opin Neurobiol 13:57-69.

McLaughlin T, Hindges R, Yates PA, O’Leary DD (2003b) Bifunctional action of ephrin-B1 as a

Feldheim DA, Kim YI, Bergemann AD, Frisén J, Barbacid M, Flanagan JG (2000) Genetic analysis of ephrin-A2 and ephrin-A5 shows their requirement in multiple aspects of retinocollicular mapping. Neuron 25:563-574.

Feldheim DA, Nakamoto M, Osterfield M, Gale NW, DeChiara TM, Rohatgi R, Yancopoulos GD, Flanagan JG (2004) Loss-of-function analysis of EphA receptors in retinotectal mapping. J Neurosci 24:2542-2550.

Gibson-Brown JJ, Agulnik SI, Silver LM, Papaioannou VE (1998) Expres- repellent and attractant to control bidirectional branch extension in dorsal-ventral retinotopic mapping. Development 130:2407-2418.

Monschau B, Kremoser C, Ohta K, Tanaka H, Kaneko T, Yamada T, Handwerker C, Hornberger MR, Löschinger J, Pasquale EB, Siever DA, Verderame MF, Muller BK, Bonhoeffer F, Drescher U (1997) Shared and distinct functions of RAGS and ELF-1 in guiding retinal axons. EMBO J $16: 1258-1267$ 
Mui SH, Hindges R, O’Leary DD, Lemke G, Bertuzzi S (2002) The homeodomain protein Vax2 patterns the dorsoventral and nasotemporal axes of the eye. Development 129:797-804.

Murali D, Yoshikawa S, Corrigan RR, Plas DJ, Crair MC, Oliver G, Lyons KM, Mishina Y, Furuta Y (2005) Distinct developmental programs require different levels of Bmp signaling during mouse retinal development. Development 132:913-923.

Nakamoto M, Cheng HJ, Friedman GC, McLaughlin T, Hansen MJ, Yoon CH, O’Leary DD, Flanagan JG (1996) Topographically specific effects of ELF-1 on retinal axon guidance in vitro and retinal axon mapping in vivo. Cell 86:755-766.

Nakamura H, O’Leary DD (1989) Inaccuracies in initial growth and arborization of chick retinotectal axons followed by course corrections and axon remodeling to develop topographic order. J Neurosci 9:3776-3795.

Ohta K, Nakamura M, Hirokawa K, Tanaka S, Iwama A, Suda T, Ando M, Tanaka H (1996) The receptor tyrosine kinase, Cek8, is transiently expressed on subtypes of motoneurons in the spinal cord during development. Mech Dev 54:59-69.

Paddison PJ, Caudy AA, Bernstein E, Hannon GJ, Conklin DS (2002) Short hairpin RNAs (shRNAs) induce sequence-specific silencing in mammalian cells. Genes Dev 16:948-958.

Padgett RW, Wozney JM, Gelbart WM (1993) Human BMP sequences can confer normal dorsal-ventral patterning in the Drosophila embryo. Proc Natl Acad Sci USA 90:2905-2909.

Peters MA (2002) Patterning the neural retina. Curr Opin Neurobiol 12:43-48.

Sakuta H, Suzuki R, Takahashi H, Kato A, Shintani T, Iemura S, Yamamoto TS, Ueno N, Noda M (2001) Ventroptin: a BMP-4 antagonist expressed in a double-gradient pattern in the retina. Science 293:111-115.

Schulte D, Cepko CL (2000) Two homeobox genes define the domain of EphA3 expression in the developing chick retina. Development 127:5033-5045.

Schulte D, Furukawa T, Peters MA, Kozak CA, Cepko CL (1999) Misexpression of the Emx-related homeobox genes cVax and mVax2 ventralizes the retina and perturbs the retinotectal map. Neuron 24:541-553.

Schulte D, Peters MA, Sen J, Cepko CL (2005) The rod photoreceptor pattern is set at the optic vesicle stage and requires spatially restricted cVax expression. J Neurosci 25:2823-2831.

Shintani T, Kato A, Yuasa-Kawada J, Sakuta H, Takahashi M, Suzuki R, Ohkawara T, Takahashi H, Noda M (2004) Large-scale identification and characterization of genes with asymmetric expression patterns in the developing chick retina. J Neurobiol 59:34-47.

Sperry RW (1963) Chemoaffinity in the orderly growth of nerve fiber patterns and connections. Proc Natl Acad Sci USA 50:703-710.

Suzuki R, Shintani T, Sakuta H, Kato A, Ohkawara T, Noda M (2000) Identifi- cation of RALDH-3, a novel retinalaldehyde dehydrogenase, expressed in the ventral region of the retina. Mech Dev 98:37-50.

Szél Á, Röhlich P, Caffé AR, Juliusson B, Aguirre G, Van Veen T (1992) Unique topographic separation of two spectral classes of cones in the mouse retina. J Comp Neurol 325:327-342.

Takahashi H, Shintani T, Sakuta H, Noda M (2003) CBF1 controls the retinotectal topographical map along the anteroposterior axis through multiple mechanisms. Development 130:5203-5215.

Turner DL, Weintraub H (1994) Expression of achaete-scute homolog 3 in Xenopus embryos converts ectodermal cells to a neural fate. Genes Dev 8:1434-1447.

Waldvogel JA (1990) The bird's eye view. Am Scientist 78:342-353.

Wong K, Peng Y, Kung HF, He ML (2002) Retina dorsal/ventral patterning by Xenopus TBX3. Biochem Biophys Res Commun 290:737-742.

Yates PA, Roskies AL, McLaughlin T, O’Leary DD (2001) Topographicspecific axon branching controlled by ephrin-As is the critical event in retinotectal map development. J Neurosci 21:8548-8563.

Yu JY, DeRuiter SL, Turner DL (2002) RNA interference by expression of short-interfering RNAs and hairpin RNAs in mammalian cells. Proc Natl Acad Sci USA 99:6047-6052.

Yuasa J, Hirano S, Yamagata M, Noda M (1996) Visual projection map specified by topographic expression of transcription factors in the retina. Nature 382:632-635. 